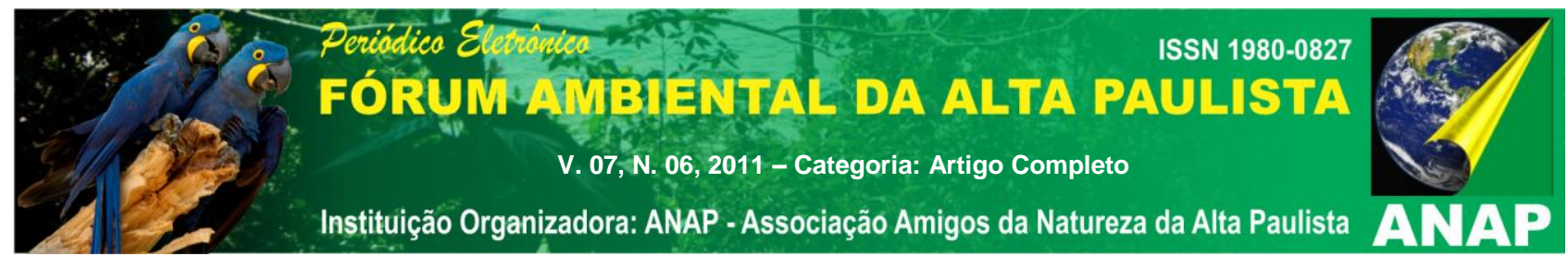

\title{
PARQUE PALEONTOLÓGICO DE SÃO JOSÉ DE ITABORAÍ - UM ESTUDO AMBIENTAL DA MATA ATLÂNTICA E DOS REGISTROS DE FÓSSEIS
}

\author{
Marcelo Souza Paula ${ }^{1}$
}

\section{Antonio Carlos de Miranda²}

RESUMO: Esta pesquisa objetivou tecer um estudo acerca da Mata Atlântica e do registro de fósseis encontrados no Parque Paleontológico de São José de Itaboraí, visando estabelecer formas, instrumentos e mecanismos de discussão no campo da Educação Ambiental. Neste sentido, a pesquisa visa ampliar o acesso ao conhecimento científico, e, portanto, democratizá-lo. Trata-se de uma investigação que se define como qualitativa, iconográfico-documental, de caráter exploratório/descritivo. Encontrado sob os resquícios de uma Mata Atlântica, com fortes indícios arqueológicos e grandes potenciais de recursos naturais, principalmente, evidenciados pela forte presença de animais e de vegetais fossilizados, que viveram na região entre 65 e 53 milhões de anos (Paleoceno/Eoceno), além de outras espécies que habitaram no período Neopleistoceno, o Parque Paleontológico de São José de Itaboraí agrega importante espaço para visitação de alunos e professores e desenvolvimento de um comportamento sócio-ambiental.

Palavras-chave: Mata Atlântica, Educação Ambiental, Fósseis vegetais.

\section{INTRODUÇÃO}

Os primeiros fósseis encontrados no município de Itaboraí, RJ, na Bacia Calcária de São José, revelaram um grande potencial a ser explorado em estudo e pesquisa. Atualmente, este local denomina-se "Parque Paleontológico de São de Itaboraí" e representa um relevante espaço destinado ao estudo da fauna e, principalmente, da flora brasileira, voltados ao campo da paleontologia, da arqueologia e da geologia.

Registros paleontológicos revelam que diferentes espécies de animais e vegetais viveram nesse local nos últimos 60 milhões de anos. A ocupação humana, estudada pela

\footnotetext{
${ }^{1}$ Mestre em Ensino de Ciências da Saúde e do Ambiente, Centro Universitário Plínio Leite. marcelo.souza@itaborai.rj.gov.br

${ }^{2}$ Professor do Curso de Pós-Graduação em Ensino de Ciências da Saúde e do Ambiente. mirantam@ig.com.br
} 


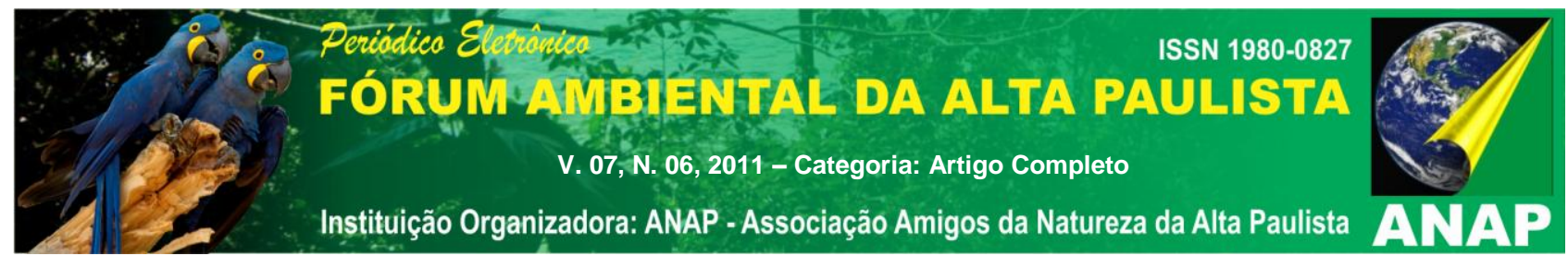

Arqueologia, é antiga e deixou também seus registros. Foram encontrados artefatos, isto é, instrumentos confeccionados pelo homem primitivo. Desta forma, sabe-se que o homem pré-histórico habitou a parte mais alta do local, hoje denominado "Morro da Dinamite".

O 'Parque' encontra-se classificado como um dos mais importantes Sítios Geológicos e Paleontológicos do Brasil, conforme consta no SIGEP (Sítios Geológicos e Paleontológicos do Brasil). Também, segundo Bergqvist, L.P.; Mansur, K. (2008), sobre este importante sítio são feitas as seguintes considerações:

O Sítio Paleontológico de São José de Itaboraí é o único depósito brasileiro conhecido que registra a primeira irradiação dos mamíferos após a extinção dos dinossauros. Por guardar fósseis dos primeiros grupos de mamíferos da linhagem moderna (Metatheria e Eutheria), é também conhecida como o "berço dos mamíferos", uma metáfora em alusão à condição primitiva dos fósseis de mamíferos lá preservados. De idade neopaleocênica, a Bacia de São José de Itaboraí, ou Bacia de Itaboraí, como é frequentemente denominada na literatura, a despeito do seu pequeno tamanho, é extremamente rica em fósseis de vertebrados e gastrópodes, sendo os mamíferos os mais abundantes e importantes e que a tornaram reconhecida no meio científico internacional. Devido à abundância, qualidade e diversidade de fósseis de mamíferos, e de sua importância para o entendimento da evolução dos mamíferos sulamericanos, uma das Idades Mamíferos-Terrestres Sul-Americanas (SALMA), foi nomeada Itaboraiense por Marshall (1985), em homenagem à Bacia de Itaboraí. (BERGQVIST, Org, 2008,1)

Encontrado ainda sob os resquícios de uma Mata Atlântica, com fortes indícios arqueológicos e grandes potenciais de recursos naturais, principalmente, evidenciados pela forte presença de animais e de vegetais fossilizados, que viveram na região entre 65 e 53 milhões de anos (Paleoceno/Eoceno), além de outras espécies que habitaram no período Neopleistoceno. O 'Parque Paleontológico de São José de Itaboraí', também chamado de "O berço dos mamíferos", foi criado no ano de 1995, por meio de lei municipal $\mathrm{n} \cong$. 1.346, tendo como principais objetivos a preservação da área, com os testemunhos da geologia original e dos fósseis remanescentes nas rochas, visando possibilitar o acesso de professores e alunos no espaço natural. 


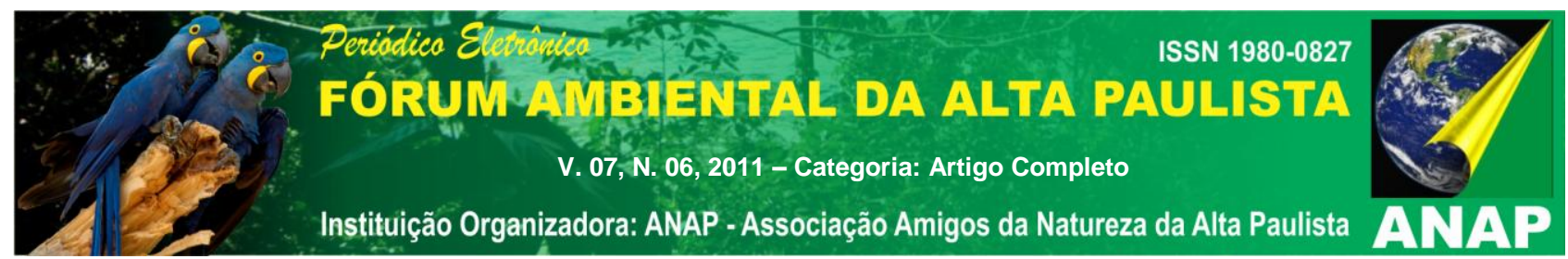

Situado sobre as regiões de Planícies Costeiras, de Tabuleiros Costeiros e de Colinas Maciços Costeiros, no Parque Paleontológico de São José de Itaboraí ainda encontram-se remanescentes de Floresta Ombrólfila Densa ${ }^{3}$.

\begin{abstract}
Este tipo de vegetação é caracterizado por fanerófitos, justamente pelas subformas de vida macro e mesofanerófitos, além de lianas lenhosas e epífitas em abundância, que o diferenciam das outras classes de formações. Porém, a característica ecológica principal reside nos ambientes ombrófilos que marcam muito bem a "região florística florestal". Assim, a característica ombrotérmica da Floresta Ombrófila Densa está presa a fatores climáticos tropicais de elevadas temperaturas (médias de $25^{\circ}$ ) e de alta precipitação, bem distribuídas durante 0 ano (de 0 a 60 dias secos), o que determina uma situação bioecológica praticamente sem período biologicamente seco. Além disso, dominam, nos ambientes destas florestas, latossolos distróficos e, excepcionalmente, eutróficos, originados de vários tipos de rochas. (Manuais Técnicos em Geociências, no. 1,16 )
\end{abstract}

\title{
Materiais e Métodos
}

A problemática desta pesquisa surge a partir da necessidade de desenvolver formas, instrumentos e mecanismos de discussão no campo da Educação Ambiental, no sentido de ampliar o acesso ao conhecimento científico, e, portanto, democratizá-lo. Sob este aspecto apresentou-se o campo de estudo, o qual originou o objeto desta pesquisa: o Parque Paleontológico de São José de Itaboraí.

Contudo, ele é pouco visitado e explorado por professores e estudantes. Portanto, trazer à tona o potencial de estudo do 'Parque', isto é, divulgá-lo, significa democratizar o acesso ao conhecimento científico. Cabe destacar que o 'Parque' se constitui como um importante espaço, principalmente pelo seu vasto campo das possibilidades de estudo, voltadas ao campo da paleontologia, da arqueologia, da geologia, da geografia, e áreas correlatas, entre elas, principalmente a Educação Ambiental.

Os procedimentos metodológicos utilizados nesta investigação a definem como qualitativa, iconográfico-documental, de caráter exploratório/descritivo. De acordo com Triviños (2006), o enfoque qualitativo de investigação visa privilegiar as práticas sociais

\footnotetext{
3 O termo Ombrófila Densa, foi criado por Ellemberg \& Mueller-Domboi (1965/6), substitui Pluvial (de origem latina) por Ombrófila (de origem grega, ambos com o mesmo significado "amigos da chuva")
} 


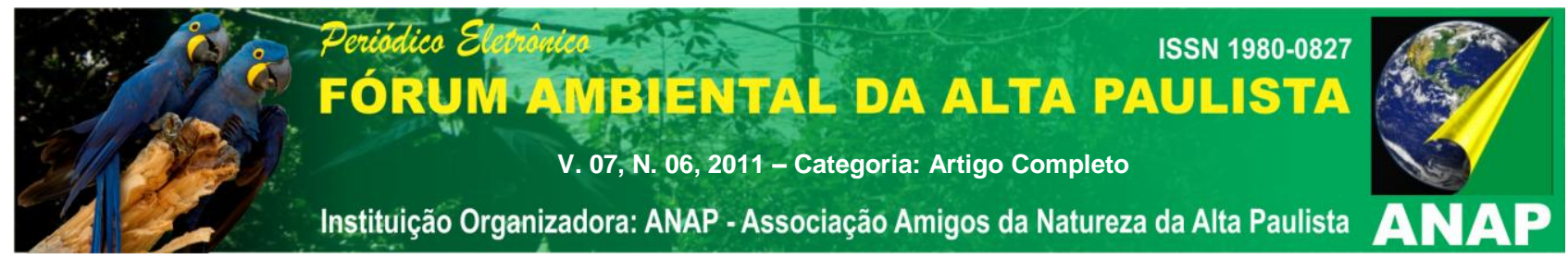

em seu ambiente, exigindo-se do pesquisador o contato direto com o contexto no qual ocorre o fenômeno educacional onde se pretende estudar. Neste sentido, o interesse pela pesquisa qualitativa deve-se em função da necessidade de entender melhor a história do espaço pesquisado, por meio de uma correlação com a questão ambiental e econômicosocial.

Outro ponto fundamental que norteia um dos objetivos desta pesquisa foi a aquisição de novos conhecimentos científicos, tendo em vista que, a partir do levantamento iconográfico, foi estabelecida a classificação científica, concebendo ao pesquisador e ao leitor a aquisição de novos saberes para este campo do conhecimento. Segundo Mertens (2007):

O conhecimento científico trata-se de um modo de conhecer que exige mais do que o saber adquirido na chave de tentativa/erro/repetição, característica do conhecimento empírico. Tendo ganhado formulação rigorosa na modernidade, ele já traz, em seu registro de nascimento, um novo modo de aprender as coisas; não como mera ocorrência fortuita, mas a partir da ralação entre essas ocorrências (efeitos) e suas causas, bem como as leis que as regem. (MERTENS, 2007,19).

Como o 'Parque' localiza-se em uma região de Mata Atlântica, em uma primeira etapa da investigação, decidiu-se pela exploração deste bioma, e como cenário, uma trilha de fácil acesso aos visitantes. Em seguida, catalogamos as espécies vegetais, ao longo dela. Identificamos um total de 16 (dezesseis) espécies vegetais: amoreira, ameixa amarela, hibisco, leucena, palmeira, cacto, bananeira, comigo-ninguém-pode, limoeiro, goiabeira, quebra-pedra, mangueira, aroeira, amendoeira, jamelão, capim dos pampas.

Cabe destacar que, dentre as espécies catalogadas, a maioria não é representação da Mata Atlântica nativa. Essas espécies também não correspondem ao total das encontradas no local, tendo em vista a vasta dimensão do parque. Entretanto, foi estabelecida uma trilha, pela facilidade de acesso, visando um maior aproveitamento, organização, maior riqueza e diversidade.

Por fim, construímos um CD e uma cartilha com um caráter de Divulgação Científica, apresentando uma descrição da Mata Atlântica, a foto, a identificação e a classificação das espécies encontradas na trilha. Além disso, uma apresentação do 'Parque', sob o enfoque geológico, ambiental e biológico. Este produto destina-se tanto 


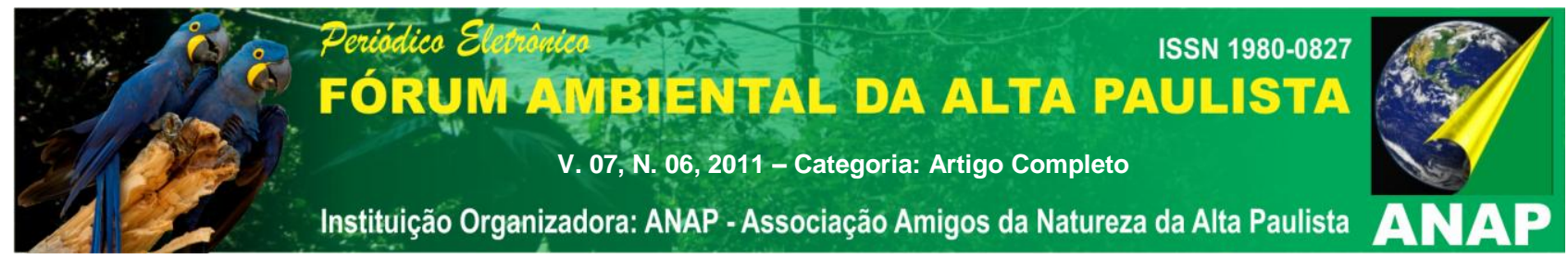

aos alunos do segundo segmento do ensino fundamental, quanto aos alunos do Ensino Médio, nas áreas das ciências naturais, biologia e disciplinas correlatas.

\section{Mata Atlântica brasileira: múltiplos olhares sobre esse importante bioma}

Os aruodores sam muj mujtos e grandes e djmfimdas maneira PERO VAZ DE CAMINHA

Denominada pelos indígenas por "caá-etê", a Mata Atlântica, atualmente, tem se tornado o centro das grandes discussões acerca da degradação e preservação ambientais. Calcula-se que nela haja cerca de 10 mil espécies vegetais que contém uma infinidade de cores, formas e odores diferentes.

Considerada pela UNESCO um patrimônio da Reserva Natural da Humanidade, a Mata Atlântica estende-se por todo litoral brasileiro e atinge cerca de 13 estados, o que corresponde a um dos ecossistemas mais ameaçados do mundo. Hoje, representa apenas cerca de $7 \%$ do que era inicialmente, sendo ocupados por grandes cidades, pastos e agricultura. Porém, ainda restam manchas da floresta por todo o litoral brasileiro. Por estar reduzida a menos de $8 \%$ de sua estensão original, a qual perfazia uma extensão $1.350 .000 \mathrm{Km} 2$ do território nacional, a Mata Atlântica encontra-se com sua cobertura vegetal natural reduzida de forma bastante considerável. Neste sentido, a dinâmica da destruição da Mata Atlântica, acelerada ao longo das últimas três décadas, resultou em alterações severas nos ecossistemas que compõem o bioma, especialmente pela perda e fragmentação de habitats.

A Mata Atlântica brasileira possui atualmente mais de 800 unidades de conservação federais e estaduais, totalizando cerca de 13.000 .000 de hectares. Considerando somente as unidades de conservação de proteção integral, são 684 unidades, as quais representam menos de $2 \%$ (cerca de 2,5 milhões de hectares) da extensão do bioma oficialmente dedicadas a esse objetivo. Importante ressaltar que essa pequena fração protegida do bioma não se encontra distribuída segundo critérios de representatividade das diferentes regiões biogeográficas, o que resulta em grandes lacunas que reduzem a efetividade do sistema em conservar a biodiversidade desta floresta. 


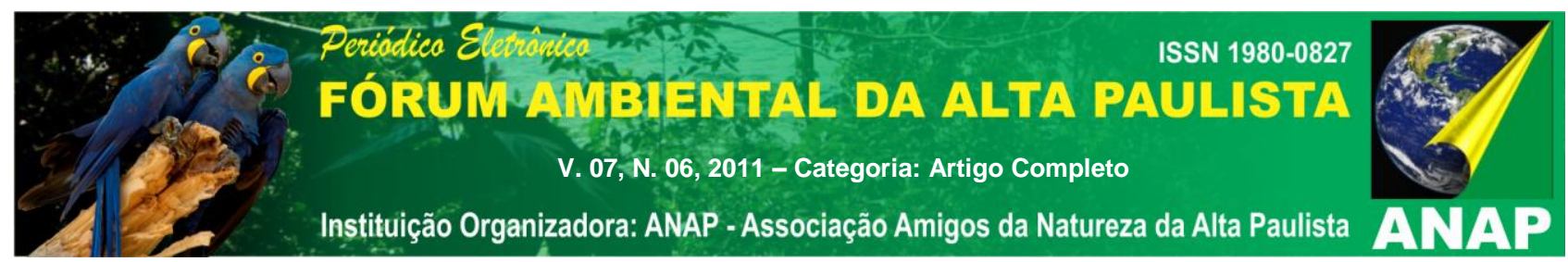

A exuberante natural Mata Atlântica brasileira já chamara atenção com a invasão dos colonizadores portugueses, em 1500, que de suas caravelas puderam ver uma paisagem diferente. Como narrou o escrivão Pero Vaz de Caminha em uma carta que fez para o Rei de Portugal,

... a hora de vésperas, avistamos terra! Primeiramente um grande monte, muito alto e redondo; depois, outras serras mais baixas, da parte sul em relação ao monte e, mais, terra chã. Com grandes arvoredos. (CAMINHA, 1500, p. 9 Apud DEAN, 1986,83).

Com a descoberta do pau-brasil e sua consequentemente derrubada para comercialização, inicia-se o processo histórico de devastação e comercialização da vegetação nativa, assim como também a ambição seus recursos naturais: o ouro e diamantes, e a busca por escravos.

Frutos de um grande processo histórico que se formaram a respeito dos nativos, os indígenas eram totalmente desvalorizados pelos seus costumes e relação que mantinham com o seu ecossistema, assim como também pelo seu conhecimento adquirido ao longo dessa relação.

Estes, entretanto, já eram capazes de atribuir nomes a centenas de espécies para as quais encontraram algum uso e sobre as quais conheceram os hábitos, estações, e, ainda relações com outras espécies.

O Século XVIII representou o início de uma tendência irreversível e cumulativa na exploração da Mata Atlântica, mesmo sendo este o período em que a ciência "descobre a floresta", através das ideias 'lluministas', porém, ainda com um papel contraditório, não somente da ciência, assim como também da tecnologia no manejo da Mata Atlântica. Contudo, esse século reduziu consideravelmente sua extensão. A mineração, a lavoura e a engorda de gado no sudeste podem ter eliminado, durante esse século, outros 30 mil $\mathrm{km}^{2}$.

Já no início do século XIX, os viajantes europeus se espantavam com os padrões de vida baixíssimos num lugar de "tamanhos bens naturais", pois se baseavam na experiência européia que havia retirado ganhos bem mais elevados de uma medíocre reserva natural. Questionavam-se onde estava a racionalidade de destruir recursos florestais para alcançar resultados tão pobres. Torna-se evidente que a floresta havia sido transformada em capital, mas não capital localmente aproveitado. O lucro que a "Mata" 


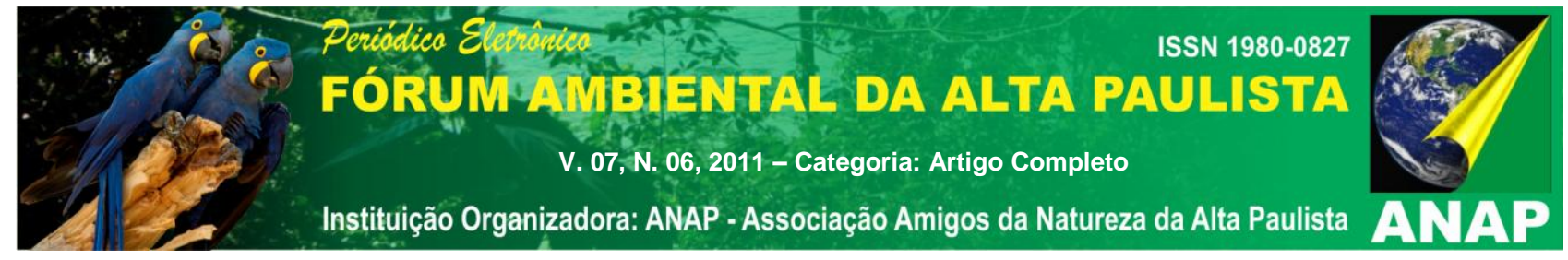

havia proporcionado durante estes três séculos de invasão estava nas cortes da Europa. Uma das conseqüências positivas para a "Mata", se não a única, com a vinda da coroa portuguesa, em 1808, para o Brasil, tornando-o sede do Império; foi que a partir daí alguns cientistas naturais renomados começariam a "descoberta", depois de significativa devastação, da diversidade da "Mata".

Um dos grandes motivos do desflorestamento no século XIX da Mata Atlântica, segundo Dean (1996), foi a consequente queimada para a plantação dos cafezais, pois se constituía naquele momento o comércio do café, o qual induzia o crescimento demográfico, a urbanização, a industrialização e a implantação de ferrovias. No final deste século, com o fim da escravidão e a implantação da República no Brasil, várias mudanças sociais, políticas e econômicas ocorreram no país, mas em nada mudaram a forma de exploração da Mata Atlântica.

A industrialização brasileira foi concomitante com a devastação da Mata Atlântica. Este processo foi intensificado durante todo o século XX. Além disso, o crescimento demográfico exercia uma pressão cada vez mais intensa sobre os recursos da Mata. Na segunda metade do século XX a política desenvolvimentista "imposta" ao Brasil após a II Guerra Mundial seria mais uma terrível ameaça contra a Mata Atlântica, ou o que sobrou dela. A obsessão pelo crescimento econômico foi a tônica das políticas do país.

A exportação alcançava, aproximadamente, quatro toneladas por ano, o que contribuía ainda mais para a devastação da Mata Atlântica, uma vez que a planta constituía parte da cobertura de solo da floresta primária. Outras plantas também foram alvos dessa comercialização, dentre elas a salsaparrilha, o cânhamo e a cinchona (conhecida no Brasil como "quina", da qual se extrai o quinino).

É difícil dizer se é correto referir-se à Mata Atlântica no tempo presente. Certa extensão de cobertura florestal ainda existe na região e, embora a maior parte seja identificável como secundária algumas pequenas faixas podem jamais ter sido derrubadas ou queimadas pelo ser humano. A maioria delas, contudo, talvez todas, sofreram algum grau de intervenção - derrubada seletiva, extrativismo ou poluição do ar, ocasionando o que hoje enfrentamos - a extinção de plantas e animais da Mata Atlântica.

\section{A Bacia Calcária de São de Itaboraí}




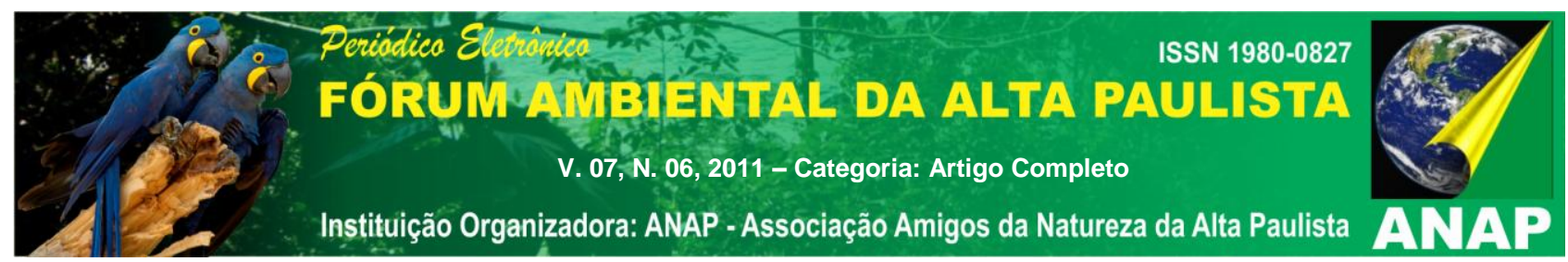

Principal formação geológica a qual originou o que hoje denominamos de Parque Paleontológico de Itaboraí, a Bacia Calcária de São José possui cerca de 60 milhões de anos (Ma) e é uma das menores bacias sedimentares brasileiras (cerca de $1 \mathrm{~km}^{2}$ de diâmetro e uma profundidade que atinge em torno de 70 metros), sendo constituída por três seqüências sedimentares: duas carbonáticas e uma terrígena.

Uma bacia sedimentar é uma depressão onde se acumulam sedimentos, produzidos pela alteração e erosão das rochas, pela ação dos rios, mares, ventos, geleira, etc., ou por processos de precipitação química. No caso da Bacia de Itaboraí, os sedimentos são principalmente de origem química, representados por rochas calcárias. A formação da bacia está relacionada com os fenômenos geológicos que ergueram a Serra do Mar e provocaram a abertura de depressões nas rochas, dentro das quais os sedimentos foram se acumulando. (Bergqvist,L.P.; Mansur,K.; Rodrigues.M.A.;Rodrigues-Francisco,B.H.;Perez,R.A.R.; Beltrão,M.C.M.C. 2008,1)

Apesar de suas reduzidas dimensões, a bacia é extremamente rica em fósseis (organismos ou vestígios de sua presença, que evidenciam a vida existente no passado da Terra). Dentre estes, podemos citar os anfíbios, os répteis, as aves, os mamíferos, os gastrópodes e os vegetais.

O tipo de vegetação predominante no entorno da bacia calcária é a capoeira/capoeirão. Segundo o glossário ambiental, capoeira/capoeirão tem o seguinte significado:

(1) Mato ralo, de pequeno porte, que nasce em lugar do mato velho derrubado. (2) Estágio arbustivo alto ou florestal baixo na sucessão secundária para floresta depois do corte, fogo e outros processos predatórios. (3) Vegetação que nasce após a derrubada de uma mata nativa, sendo, portanto uma vegetação secundária (ARRUDA et allii, 2001). (4) O mesmo que mata natural regenerada. (5) Termo brasileiro que designa o terreno desmatado para cultivo. Por extensão, chama-se capoeira a vegetação que nasce após a derrubada de uma floresta. Distinguem-se as formas: capoeira rala; capoeira grossa, na qual se encontram árvores; capoeirão, muito densa e alta. Essas formas correspondem a diferentes estágios de regeneração da floresta. Vegetação secundária que nasce após a derrubada das florestas virgens. Mato que substitui a mata secular derrubada. (6) Termo popular usado para designar áreas abandonadas onde a vegetação começa a se recuperar sozinha; serve tanto para designar os primeiros estágios de recuperação (campo sujo) como para estágios mais avançados (mata secundária incipiente). 


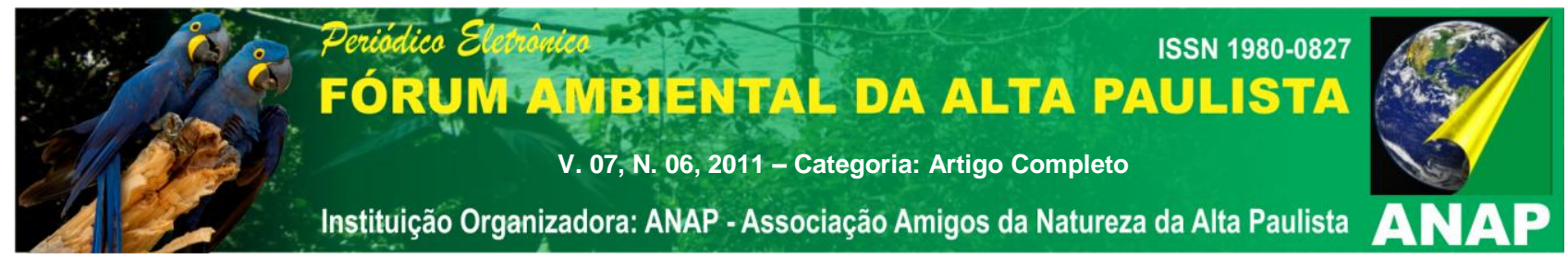

(Disponível em http://ambientes.ambientebrasil.com.br/educacao. Acesso em 30/03/2010).

Economicamente, a Bacia Calcária de São José de Itaboraí foi marcada por relevantes momentos históricos. Inicialmente comprada pelos franceses e logo após pelos americanos, a bacia tornou-se espaço de cobiça pelo mercado, gerada em função da sua grande concentração de caulim, também utilizado na fabricação de cimento, do tipo Portland.

Durante cerca de 50 anos, a Companhia Nacional de Cimento Portland - CNCP explorou o calcário da Bacia de São José de Itaboraí, produzindo cimento. Grandes construções históricas como o estádio do Maracanã e a Ponte Rio-Niterói foram realizadas com o cimento produzido a partir do calcário da jazida de São José de Itaboraí.

Os milhares de fósseis coletados na Bacia de Itaboraí, durante os 50 anos de sua exploração econômica, estão depositados em instituições de ensino e pesquisa do Rio de Janeiro (Museu de Ciências da Terra, Departamento Nacional da Produção Mineral DNPM, Museu Nacional e Departamento de Geologia, Universidade Federal do Rio de Janeiro - UFRJ) e ao American Museum of Natural History, em Nova lorque, EUA.

Em inícios da década de 80, quando o processo devastador cessou, por perceber que seu principal minério havia diminuído de forma consideravelmente, não gerando mais lucro para a empresa de cimento, a bacia foi abandonada e a empresa buscou outra fonte com maior potencial de minério, no momento, encontrada na cidade de Cantagalo - RJ, para onde se instalou. Entretanto, em função da grande cava deixada pela empresa, as águas da chuva e também subterrâneas, começam formar um lago artificial, o que atualmente denomina-se de bacia calcária.

No que concerne à sua importância no campo da Geologia, segundo Bergqvist, Moreira e Pinto (2006), a primeira descrição e o primeiro perfil geológico de Itaboraí foram elaborados por LEINZ (1938), que distinguiu três seqüências distintas no preenchimento da bacia: calcário fitado, ocorrendo em bancos irregulares e lentiformes com dezenas de metros de comprimento e alguns metros de espessura, afossílifero, passando em alguns pontos a calcário oolítico.

Tecendo uma conclusão sobre as espécies vegetais encontradas na bacia calcária de São José de Itaboraí, em consoante com uma visão ainda ambiental, Schröter (1934) apud Beurlen e Sommer (1954), são feitas as seguintes considerações: 


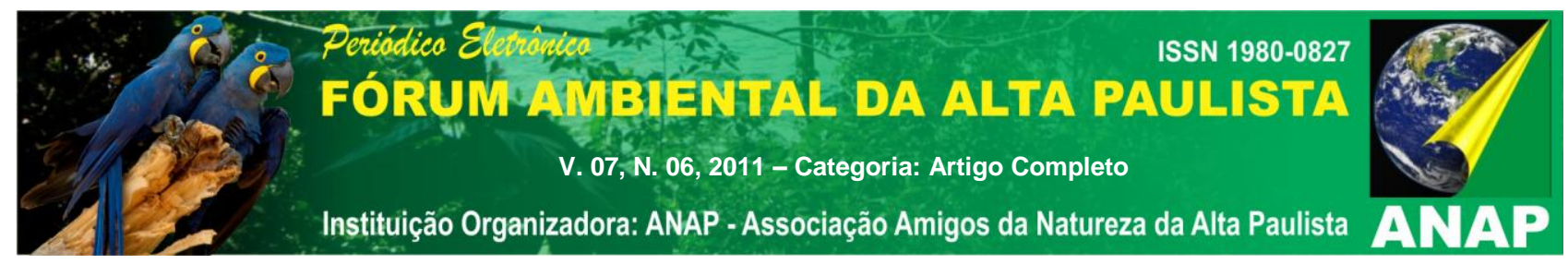

Quanto mais velha a flora, tanto mais se encontram seus elementos em equilíbrio ecológico, tendo alcançado seus limites pelo ciclo de erosão e concorrência; constituem formas "estáveis", mostram constância na sua distribuição com simultânea vitalidade total e ajustamento harmônico ao ambiente, apagando os vestígios da sua história de imigração. (BEURLEM \& SOMMER, 1954,20).

\section{REGISTRO DE FÓSSEIS NA BACIA CALCÁRIA DE SÃO JOSÉ DE ITABORAÍ}

A seguir, apresentamos um gráfico que descreve os vestígios fósseis de animais e vegetais procedentes da Bacia de São José sob a seguinte proporcionalidade.
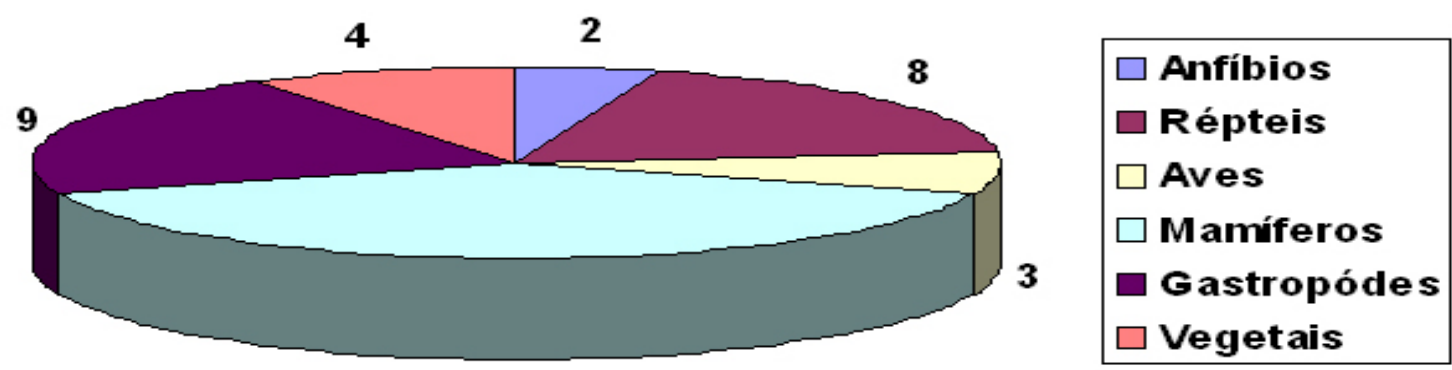

17

Figura: Diagrama comparativo do número de famílias de macrofósseis animais e vegetais procedentes da bacia de Itaboraí.

Fonte: Bergqvist, L. P., et alli (2008)

Observa-se que a presença de vegetais fósseis foi determinante para o estudo da datação e de descobertas das condições de vida ocorridas neste espaço, há 60 milhões de anos, logo após a extinção dos dinossauros. Contudo, é a quarta maior concentração de espécies ocupando a bacia.

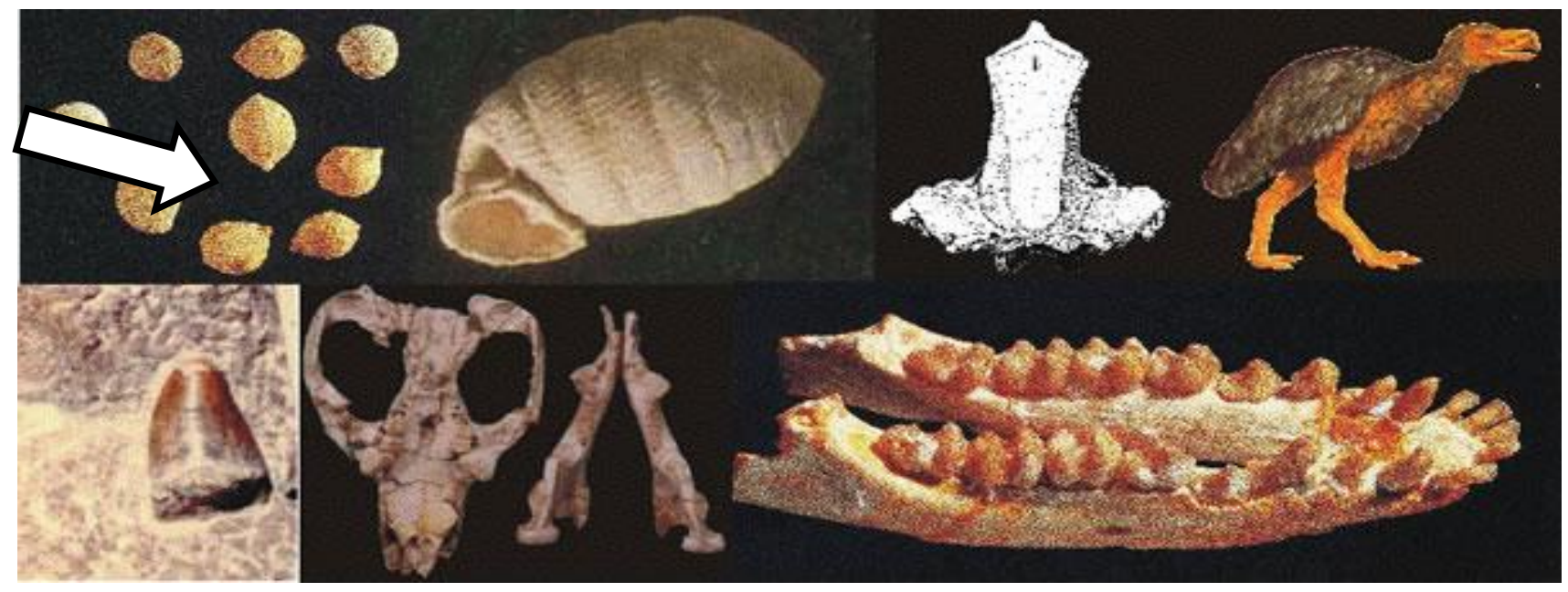




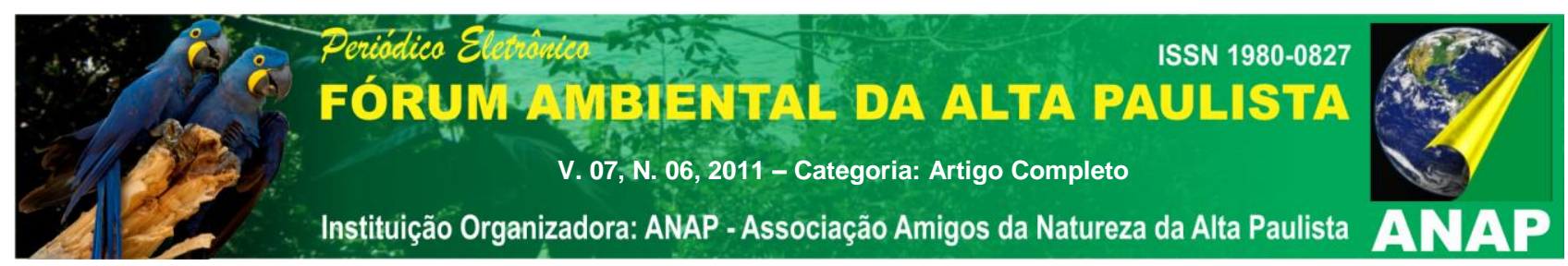

Figura: Da esquerda para a direita e do alto para baixo - Fósseis da bacia: sementes, gastrópode, fragmento de crânio de rã, ave, dente de crocodilo, crânio e mandíbula de marsupial e mandíbula do ancestral de uma forma similar ao cavalo.

Fonte: http://www.caminhosgeologicos.rj.gov.br/pg_placa.phpp=3. Acesso em 14/03/2010.

No tocante aos vestígios fósseis vegetais, pode-se perceber que os mesmos eram encontrados a partir de sementes fossilizadas em árvores denominadas de "grão-de-galomoído", plantas ornamentais exóticas cultivadas no Brasil, ainda existentes nos arredores da bacia. Estes vestígios representam a época do Paleoceno, da era Cenozóica, despontando ainda para a era Mesozóica, no período do Cretáceo.

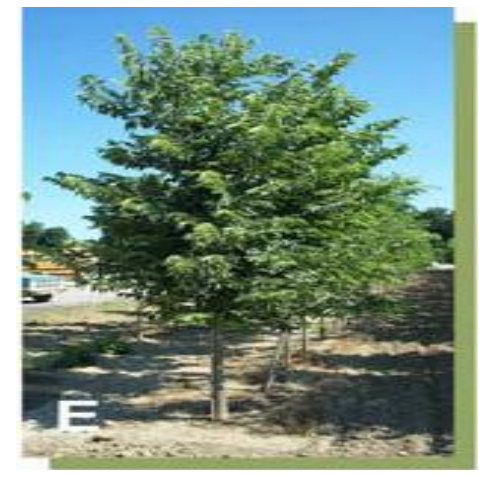

Figura: grão-de-galo-moído.

Fonte: Fonte: Bergqvist, L. P., et ali (2008)

Dois importantes vegetais fósseis foram encontrados na bacia: a impressão de uma folha dicotiledônea, filiada às mirtáceas, gênero Psidium e pequenos caroços atribuídos às monocotiledôneas, família das ciperáceas, gênero Acrocarpus (Beurlen \& Sommer, 1954). Este foi considerado importante material fitopaleontológico, o qual deu sustentação para as pesquisas que apresentam a datação da região, por meio dos microfósseis.

No que se referem às sementes (caroços), ocorreram muitas indagações pelos pesquisadores, visto que os dois vegetais fósseis encontrados na bacia calcária não representavam a maioria das espécies local, uma vez que os vestígios animais que concentravam maior quantidade.

A partir dessa observação, o material tornou-se fruto de comparações com outras espécies encontradas, principalmente nos Estados Unidos da América através de uma pesquisa patrocinada pelo Conselho Nacional de Pesquisas, em 1952. 


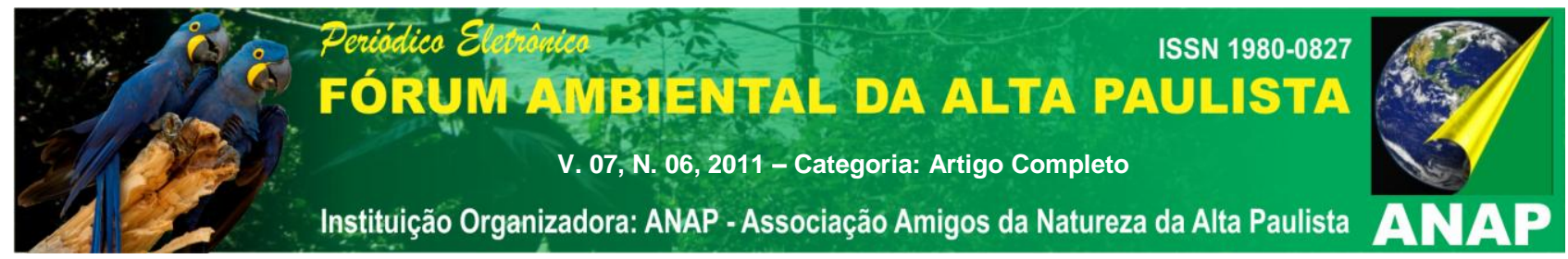

O traçado histórico de exploração do 'Parque' envolveu a inicialmente a classificação do material fóssil encontrado na bacia, a análise, e a comparação com outras espécies. Torna-se oportuno destacar um trecho de Stanley A. Cain (1951) citado por Berulen \& Sommer (1954):

El mejor método para la identificación de los fósiles consiste em la camparación de los mismos com formas actuales equivalentes, si los fósiles non son muy antigos, o la búsqueda de alguma guia entre los miembros de lãs asociaciones ecológicas naturales, para ubicarlos dentro del gênero. (CAIN, 1951, Apud BEURLEN; SOMMER 1954, 13)

Mediante todo o esforço para estabelecer uma classificação sistemática própria, em 1950, o Professor Júlio Magalhães, titular da cadeira de Paleontologia da Faculdade Nacional de Filosofia, após várias comparações e estudos, estabeleceu uma classificação taxonômica para os caroços encontrados:

- Classe: Dicotyledôneae

- Família: Ulmaceae

- Gênereo: Celtis

- Espécie: Celtis santosi (Magalhães)

(MAGALHÃES, 1950, pag. 42)

Por sua vez, Beurlen e Sommer (1954), assim descrevem os caroços:

Descrição do holótipo: "Trata-se de pequenos frutos epigenizados, de forma globulosa, com as seguintes dimensões: maior diâmetro $-5 \mathrm{~mm}$, e menor, $4 \mathrm{~mm}$; a superfície é rugosa, notando-se, perfeitamente, três cristas, uma das quais, mais saliente, que devem corresponder aos carpelos formadores do ovário trigono. Alguns desses pequenos frutos acham-se cheios e um, de que tivemos a felicidade de obter um bom corte, foi encontrado vazio, com septos internos, parecendo que, no primeiro caso, o ovário se desenvolveu após a fecundação, e no segundo, sem fecundação" (BEURLEM \& SOMMER, 1954,16).

Pelo fato dos caroços, ora estudados se tratarem da família das Ulmaceae e estes serem considerados de origem, eminentemente, tropical, é possível concluir que o clima na época era semelhante ao de hoje. Corrobora ainda para este fato a espécie do outro fóssil vegetal, a folha filiada do gênero Psidium, conforme relatado por Beurlem e Sommer (1954). Entretanto, os mesmos autores informam ainda que, segundo Magalhães (1950), 


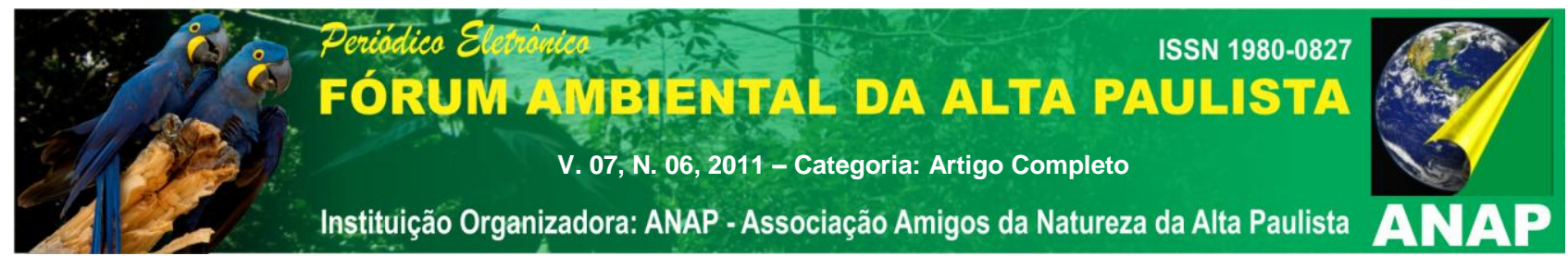

não existem dados suficientes para uma comprovação total do fato pertinente ao seu clima.
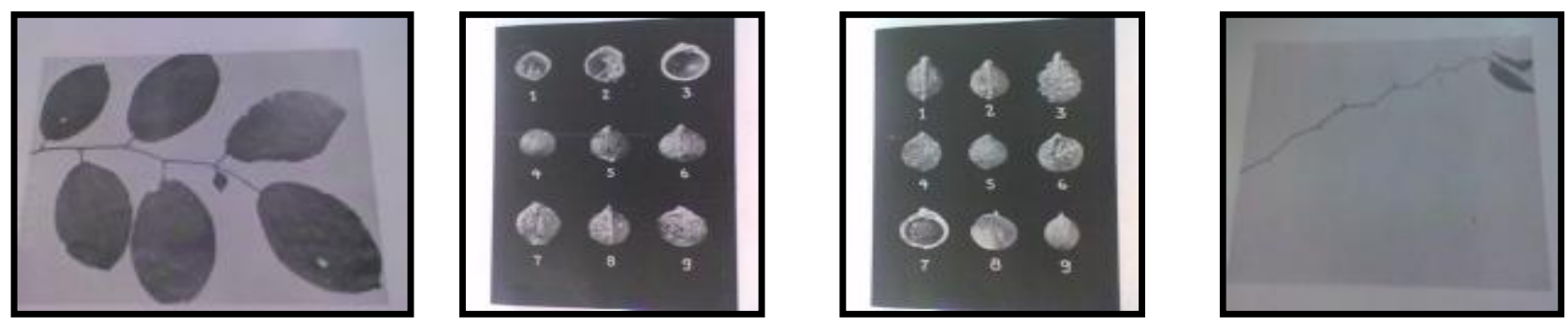

Figura: Foto: Da esquerda para a direita: 1 (Ramo de Celtis brasiliensis com folhas e frutos; 2 e 3 (holótipo, Celtis santosi, partes interna e externa do caroço fóssil); 4 Ramo de $\mathrm{C}$. brasiliensis

Fonte: Boletim №. 149 - Divisão de Geologia e Mineralogia/1954 - estampas I, II e III.

O Quadro abaixo representa as diferentes idades atribuídas à Bacia de São José de Itaboraí com base em sua biota. Contudo, observa-se a importante participação dos vegetais dentro deste contexto. O quadro se encontra organizado segundo os seguintes períodos: I - Cretáceo Superior; II - Paleoceno inferiror; III Paleoceno "Médio"; IV Paleoceno Superior; V - Paleoceno; VI - Eoceno inferior; VII Mioceno; VIII - Plioceno.

\begin{tabular}{|c|c|c|c|c|c|c|c|c|}
\hline \multirow{2}{*}{ BIOTA/REFERÊNCIA } & \multicolumn{8}{|c|}{ IDADE } \\
\hline & $\mathbf{I}$ & II & III & IV & $\mathbf{V}$ & VI & VII & VIII \\
\hline $\begin{array}{c}\text { Fauna de Gastrópodes (OLIVEIRA, } \\
1933 \text { ) }\end{array}$ & & & & & & & & $\mathbf{x}$ \\
\hline $\begin{array}{c}\text { Moldes de Gastrópodes } \\
\text { (MAURY, 1935) }\end{array}$ & & & & & & & $\mathbf{X}$ & $\mathbf{X}$ \\
\hline $\begin{array}{c}\text { Australorbis } \\
\text { (MEZZALIRA, 1946) }\end{array}$ & & & & & & & $\mathbf{X}$ & \\
\hline $\begin{array}{c}\text { Dentes de Mamíferos } \\
\text { (PRICE \& PAULA-COUTO, 1946, b) }\end{array}$ & & & & & & $\mathbf{X}$ & & \\
\hline $\begin{array}{l}\text { Carodnia, Colbertia e Tetragonostylops } \\
\text { (PAULA-COUTO, 1949) }\end{array}$ & & & & & $\mathbf{X}$ & $\mathbf{X}$ & & \\
\hline $\begin{array}{c}\text { Vegetais } \\
\text { (MAGALHÃES, 1950) }\end{array}$ & & & & & & $\mathbf{X}$ & & \\
\hline Mamíferos (PAULA-COUTO, 1952 a) & & & & $\mathbf{X}$ & & & & \\
\hline Gastrópodes (PAULA-COUTO, 1953) & $\mathbf{X}$ & $\mathbf{X}$ & & & & & & \\
\hline Gastrópodes (PARODIZ, 1969) & & & & & & & $\mathbf{X}$ & \\
\hline Vertebrados (PARODIZ, 1969) & & & & & $\mathbf{X}$ & & & \\
\hline $\begin{array}{c}\text { Gastrópodes (FERREIRA \& COELHO, } \\
\text { 1970) }\end{array}$ & $\mathbf{X}$ & $\mathbf{X}$ & & & & & & \\
\hline $\begin{array}{l}\text { Calcário com mamíferos (BRITO et al., } \\
1972)\end{array}$ & $\mathbf{X}$ & & & & & & & \\
\hline
\end{tabular}




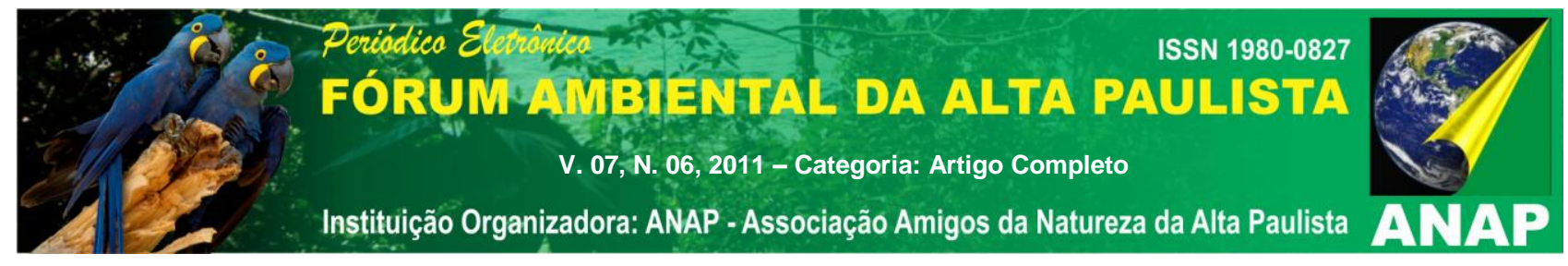

\begin{tabular}{|c|c|c|c|c|c|c|c|c|}
\hline $\begin{array}{c}\text { Mamíferos e moluscos associados, no } \\
\text { calcário cinza (SOUZA-CUNHA et al., } \\
\text { 1972) }\end{array}$ & & $\mathbf{X}$ & & & & & & \\
\hline $\begin{array}{c}\text { Epidolops e Catrodnia (MARSHALL, } \\
\text { 1985) }\end{array}$ & & & $\mathbf{X}$ & & & & & \\
\hline $\begin{array}{c}\text { Palinomorfos (SOUZA-CUNHA et al., } \\
\text { 1980) }\end{array}$ & & & $\mathbf{X}$ & & & & & \\
\hline $\begin{array}{c}\text { Palinomorfos (LIMA \& SOUZA- } \\
\text { CUNHA), 1986) }\end{array}$ & & & & & $\mathbf{X}$ & & & \\
\hline $\begin{array}{c}\text { Mamíferos (MEDEIROS \& } \\
\text { BERGQVIST, 1999) }\end{array}$ & & & & $\mathbf{X}$ & & & & \\
\hline
\end{tabular}

Figura: Quadro representando as idades da bacia calcária

Fonte: Ignácio Machado Brito

Vale lembrar que segundo Magalhães (1950), o vestígio de fósseis vegetais retrata um período transitório entre o Paleoceno e o Eoceno Inferior.

Em relação à sua importância no campo da Paleontologia, Caniné e Francisco (2000) tecem as seguintes considerações:

Além desta importância para o Estado do Rio de Janeiro, possui, também, valor em escala continental e mundial, devido aos fatores, os quais se encontram expostos a seguir: a) Terciário (fósseis mais antigos) gastrópodes pulmonados, indicadores de fauna continental, sendo a maioria constituída por caramujos de mato e alguns tipicamente aquáticos, e por restos de vegetais (principalmente sementes); b) Paleoceno Superior (aproximadamente 55 milhões de anos)- mamíferos primitivos, restos de lagartos, cobras e tartarugas. Estes mamíferos primitivos são representantes dos primeiros grupos a se irradiarem em ampla escala no planeta, após a extinção em massa dos dinossauros há 65 milhões de anos; e c) Pleistoceno (1,8 milhões a 8.000 anos) megafauna, representada por mastodontes e preguiça-gigante.(CANINÉ; FRANCISCO, 2000, 12)

Neste sentido, percebe-se que a Bacia Calcária possui vestígios que registram relevantes contribuições para os estudos das Eras Geológicas. As presenças de fósseis, tanto de animais quanto de vegetais corroboram para esta constatação. Contudo, a identificação, através de artefatos, possibilitou a identificação de uma datação de pelo menos $1 \mathrm{Ma}$ (Pleistoceno médio).

Os milhares de fósseis coletados na Bacia de Itaboraí, durante os 50 anos de sua exploração econômica, estão depositados em instituições de ensino e pesquisa do Rio de Janeiro (Museu de Ciências da Terra, Departamento Nacional da Produção Mineral DNPM, Museu Nacional e Departamento de Geologia, Universidade Federal do Rio de Janeiro - UFRJ) e ao American Museum of Natural History, em Nova lorque, EUA. 


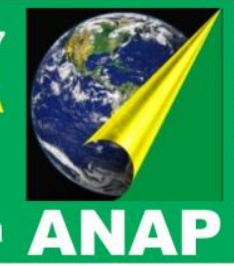

\section{CONSIDERAÇÕES FINAIS}

O panorama construído historicamente pela sociedade local no tocante ao Parque Paleontológico de São José de Itaboraí tem demonstrado uma grande preocupação quanto ao seu futuro sustentável, principalmente no que tange ao seu potencial histórico, econômico, social e científico.

No campo educacional, este estudo nos levou a perceber que o 'Parque' pode se constituir como importante recurso para o processo de construção do conhecimento científico, tendo em vista ser um grande laboratório a céu aberto, proporcionando assim um momento importante para o desenvolvimento da Divulgação Científica.

Nesse contexto, a Bacia Calcária de São José de Itaboraí, após grandes escavações, ainda guarda uma imensa riqueza histórica. $O$ encontro de fósseis por pesquisadores traz à tona toda uma discussão acerca de sua importância no campo da ciência, mais precisamente na paleontologia, arqueologia, geologia e geografia e, principalmente, no campo da Educação Ambiental. Nesse caso, a visita ao 'Parque' (ou o estudo e o conhecimento da sua riqueza histórica através de textos, artigos, vídeos) pode se transformar em uma importante estratégia de ensino aprendizagem e despertar nos estudantes o respeito ao meio ambiente, por um lado, através do estudo de sua história recente (a exploração, a degradação do solo, a urbanização) e da sua história geológica (os fósseis, a idade da Terra), e, por outro lado, ao permitir envolver temas interdisciplinares como, por exemplo, o estudo da Mata Atlântica, entre outros.

\section{REFERÊNCIAS}

BERGGVIST, Lílian Paglarelli; MOREIRA, Adraiana Lima; PINTO, Danille Ribeiro. Bacia de São José de Itaboraí - 75 anos de história e ciência. Serviço Geológico do Brasil FAPERJ, Rio de Janeiro: 2006.

BEURLEN, Karl \& SOMMER, Friedrich Wilhelm. Restos Vegetais Fósseis e Tectônica da Bacia Calcária de Itaboraí, Estado do Rio de Janeiro, Divisão de Geologia e Mineralogia Departamento Nacional de Produção Mineral - UFRJ. Rio de Janeiro: Boleteim no 19, 1954. 


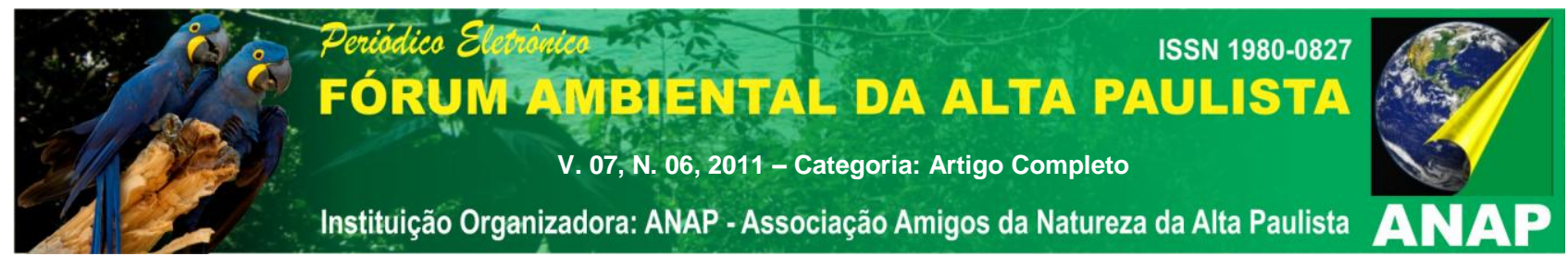

BRITO, Ignácio Machado. Bacias Sedimentares e formações pós-paleozóicas do Brasil. Editora Interciências. Rio de Janeiro: 1979.

CAMINHA, Pero Vaz. Carta a Dom João. São Paulo: Abril Educação, 1982.

CISNERO, Juan. Entendendo o Registro Fóssil e a Paleontologia. Biociência.org. 2004.

CORRÊA, M. Pio. Dicionário das Plantas Úteis do Brasil. Ministério da Agricultura. Instituto Brasileiro de desenvolvimento Florestal. Rio de Janeiro: 1926-1978.

CRUZ, Silvana. Educação Ambiental e fraternidade na Amazônia: novos desafios para a sustentabilidade. Fórum Ambiental da Alta Paulista. ANAP Associação Amigos da Natureza de Alta Paulista, Volume III, 2007.

DEAN, Werren. A ferro e fogo. A História e a Devastação da Mata Atlântica Brasileira. São Paulo: Companhia das Letras, 1996.

DIAS, Genebaldo Freire - Ph.D. Educação Ambiental: princípios e práticas. 9 ed. São Paulo: Gaia, 2004.

ELIAS, Diego. Paleontologia: Estudo do ensino e dos materiais didáticos de Biologia utilizados nas Escolas Públicas do ensino médio de Itaúna - MG. Minas Gerais: 2008.

FARIAS, Carlos Eugênio Gomes. Mineração e Meio Ambiente no Brasil. Relatório preparado para o PNUD. Ano 2002.

FERREIRA, Leandro de Santis; MARSOLA, Fábio Júnio \&TEIXEIRA, Simone de Pádua. Anatomia dos órgãos vegetativos de Dieffenbachia picta Schott (Araceae) com ênfase na distribuição de cristais, laticíferos e grãos de amido. Rev. bras. farmacogn. vol.16 suppl.0 João Pessoa Dec. 2006

GOMES, Gestão de Recursos Hídricos: novos conceitos para a Educação Ambiental. Fórum Ambiental de Alta Paulista. Volume III. Ano 2007.

GUATTARI, Felix. As Três Ecologias. Trad. Maria Cristina F. Bittencourt. 19 ed. São Paulo: Papirus, 2008.

GUIMARÃES, Vanize de Freitas; MENEZES, Sebastião de Oliveira. Uso de Trilha Interpretativa na Educação Ambiental: uma proposta para o município de Rosário da Limeira (MG). II Fórum Ambiental da Alta Paulista. Outubro de 2006.

GUIMARÃES, Mauro. A Dimensão Ambiental na Educação. 8 ed. São Paulo: Papirus, 2007. 


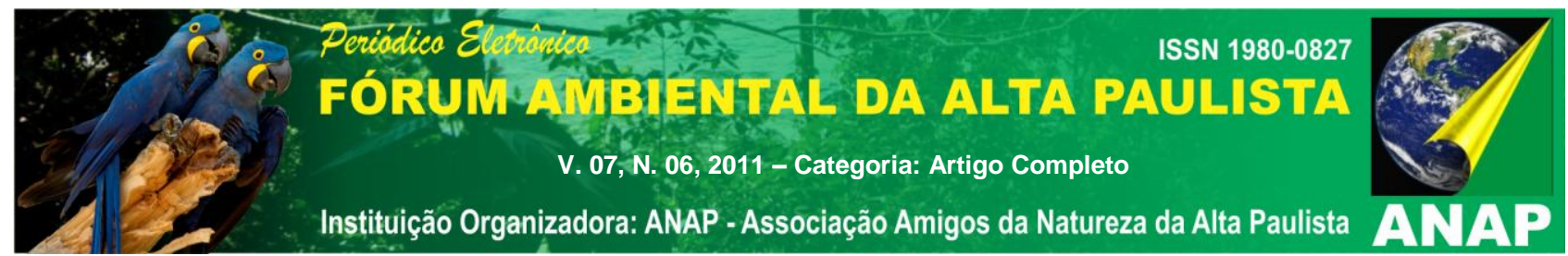

JULIÃO, Danielle; IKEMOTO, Silva Marie \& COSTA, Vivian Castilho da. Elaboração de Trilhas e Rotas Interpretativs em Manguezais: Área de proteção Ambiental, Guapimirim, RJ. II Encontro Interdisciplinar de Ecoturimso em Unidades de Conservação. VI Congresso Nacional de Ecoturismo. Itatiaia - RJ. Novembro/2007.

MASSARANI, Luisa; MOREIRA, Ildeu de Castro; BRITO, Fátima (Org). Ciência e público: caminhos da divulgação científica no Brasil. Rio de Janeiro: Casa da Ciência - Centro Cultural de Ciência e Tecnologia da Universidade Federal do Rio de Janeiro. Fórum Ciência e Cultura, 2002.

MINISTÉRIO DO MEIO AMBIENTE. Instrução Normativa. Lista Oficial das Espécies da Flora Brasileira Ameaçadas de Extinção. Brasília. 2008.

MORIN, Edgar (2002). A Cabeça Bem-Feita: Repensar a reforma, reformar o pensamento. Trad. Eloá Jacobina. $7^{\mathfrak{a}}$ ed. Rio de Janeiro: Bertrand Brasil.

OBERHERR, Andréa Diana. Trilhas Ecológicas como Instrumento de Educação Ambiental. Universidade Federal de Santa Maria - RS: 2008.

SECRETARIA DE PLANEJAMENTO, ORÇAMENTO E COORDENAÇÃO. Fundação Instituto Brasileiro de Geografia e Estatística - IBGE. Manual Técnico da Vegetação Brasileira, no 1: Rio de Janeiro, 1992.

SENA, Paulo Sergio de. Emille Durkheim e as áreas naturais protegidas: proposta de "nomia" para a "anomia sócio-ambiental" do industrialismo.Revista Âmbito Jurídico. Rio Grande, 27, 31/03/2006.

SOUZA, José Carlos Moreira de. A educação ambiental na recuperação e conservação de recursos naturais: a percepção dos parceleiros do assentamento poções - Rialma (GO). Dissertação, Instituto de Agronomia - UFRRJ. Rio de Janeiro: 2009. 